\title{
O Trabalho como Estratégia de Atenção em Saúde Mental: Um Estudo Documental
}

\author{
Work as a Mental Health Care Strategy: A Documentary Study
}

El Trabajo como Estrategia para la Atención de la Salud Mental: Un Estudio Documental

\author{
Eneida Santiago ${ }^{1}$ \\ Universidade Estadual de Londrina (UEL) \\ Silvio Yasui \\ Universidade Estadual Paulista "Júlio de Mesquita Filho", campus Assis (Unesp-Assis)
}

\begin{abstract}
Resumo
Cartografamos o discurso político em que se articula o trabalho com ações de atenção em saúde. No Brasil, o universo legal da saúde mental que trata do trabalho distingue-se em anterior e posterior à Reforma Psiquiátrica. Antes, juridicamente sustentadas, as atividades de trabalho eram um instrumento de medida da ocupação do tempo livre e de avaliação da eficácia dos tratamentos manicomiais. Após a Reforma, a presença do trabalho como estratégia de atenção é crescente. A produção discursiva legal da saúde mental assumiu diretrizes como a reabilitação psicossocial e a restauração da cidadania, utilizando, como proposta, a (re)inclusão social pelo trabalho. No entanto as políticas trazem uma heterogeneidade conceitual do que se considera trabalho, com poucos esclarecimentos de suas condições concretas, aspectos que dificultam que o trabalho como estratégia de atenção propicie a (re)invenção do sofrimento psíquico intenso.

Palavras-chave: trabalho, política pública, saúde mental, Sistema Único de Saúde, saúde coletiva
\end{abstract}

\begin{abstract}
We map the political discourse in which work is articulated with health care actions. In Brazil, the legal universe of mental health that addresses work is divided in before and after the Psychiatric Reform. Previously, legally supported work activities were an instrument for measuring leisure time occupation and evaluating the effectiveness of asylum treatments. After the Reform, the presence of work as a care strategy has increased. The legal discursive production of mental health has taken on guidelines such as psychosocial rehabilitation and restoration of citizenship, using, as one of the instruments, social (re)inclusion through work. However, policies present a conceptual heterogeneity of what is considered work, with little clarification of its concrete conditions, aspects that make it difficult for work as a care strategy to foster the (re)invention of intense psychic suffering.

Keywords: Work, Public Policy, Mental Health, Brazilian National Health Service, Public Health
\end{abstract}

\section{Resumen}

Mapeamos el discurso político en el que el trabajo se articula con las acciones de atención médica. En Brasil, el universo legal de la salud mental que se ocupa del trabajo se distingue antes y después de la Reforma Psiquiátrica. Anteriormente, las actividades laborales con apoyo legal eran un instrumento para medir la ocupación del tiempo libre y evaluar la efectividad de los tratamientos de asilo. Después de la Reforma, la presencia del trabajo como estrategia de atención está aumentando. La producción discursiva legal de la salud mental asumió pautas tales como la rehabilitación psicosocial y la restauración de la ciudadanía, utilizando, como uno de los instrumentos, la (re)inclusión social a través del trabajo. Sin embargo, las políticas aportan una heterogeneidad conceptual de lo que se considera trabajo, con poca aclaración de sus condiciones concretas, aspectos que dificultan el trabajo como estrategia de atención para propiciar la (re)invención del intenso sufrimiento psíquico.

Palabras clave: trabajo, política pública, salud mental, Sistema Único de Salud, salud pública

\footnotetext{
${ }^{1}$ Endereço de contato: Rodovia Celso Garcia Cid (PR 445), Km 380, Campus Universitário, Londrina, PR. CEP 86057-979. E-mail: eneidasantiago2@gmail.com; esantiago@uel.br
} 


\section{Introdução}

Dedicamo-nos, ao longo destas páginas, a cartografar a constituição do discurso político que pronunciou as estratégias do trabalho como política de saúde mental a partir do Sistema Único de Saúde (SUS) (Ministério da Saúde, 2004). A categoria trabalho enquanto proposição articuladora de atenção para aqueles mentalmente adoecidos se faz presente desde os primeiros textos legislativos, que abordavam a alienação mental, até os documentos mais recentes, como o do SUS e o da Lei 10.216/2001. Por meio de diálogos firmados com alguns analisadores foucaultianos (biopolítica e normalização), analisamos a composição de forças dessas proposições e os conceitos de trabalho que alimentaram os agenciamentos discursivos, bem como os sentidos que emergiram dessas produções. Levantamos como hipótese que há uma significativa presença da temática trabalho nas legislações e políticas de saúde mental, ao mesmo tempo em que um repertório de conceituações envolvendo tal ação se faz presente no interior e nas adjacências desses escritos. Essas conceituações, que serão cartografadas e por nós analisadas, são a de trabalho, de trabalhar e do sujeito que trabalha. Entendemos por trabalho a atividade orientada para um fim. Por trabalhar, o processo que demanda investimentos objetivos e subjetivos para alcançar a finalidade, e o do sujeito que trabalha, como o sujeito realiza ou se envolve em uma atividade de trabalho, mesmo que essa não seja social e/ou juridicamente reconhecida. Quanto às possibilidades da experiência trabalho em suas intercessões interventivas, somos mobilizados pela análise de que tipo e que condições de trabalho tais documentos consideram terapêuticos.

Para produzir tais indagações, a cartografia foi escolhida. Como enunciação dos estudos realizados, de passeios por percursos ora familiares ora desconhecidos e como possibilidade da valorização de representações das realidades vividas e percebidas, a cartografia se mostrou potente. Encontros e afetações, embora não sendo a finalidade do processo sucessivo de aproximação e distanciamento, são parte integrante do movimento de conhecer. As cartografias se compõem por desenhos de paisagens que se fazem ao mesmo tempo em que se transformam. Dessa forma, neste texto, as cartografias foram construídas a partir de nossas experiências de leituras e análises de documentos jurídicos com o propósito de dar expressividade aos campos de encontro entre trabalho e atenção em saúde mental. Os documentos selecionados foram os textos legislativos de assistência psiquiátrica do fim da Primeira República até a atual Política Nacional de Saúde Mental, aprovada em 2001. Como orientador para nossa trajetória, assumimos os objetivos de interrogar esses escritos sobre o(s) conceito(s) de trabalho apresentado(s), as formas e os sentidos sobre os quais esses conceitos arquitetam o trabalho como estratégia de atenção em saúde mental, as ações que são orientadas por esses conceitos e as possibilidades políticas e subjetivas que são produzidas pelos conceitos proferidos.

\section{Trabalho e Produção de Si}

Apreendemos, neste artigo, o trabalho em sua dupla possibilidade: enquanto atividade dirigida com o fim de criar valor, sendo calibrada por relações econômicas e produtivas, e também do trabalho em suas potencialidades de subjetivações. Qualquer esboço de definição de trabalho deve, obrigatoriamente, contemplar as dimensões de produção de si e de produção de trocas nos âmbitos materiais, subjetivos e sociais (Dejours, 1993; 2004). Todavia 
Dejours (2004) sinaliza que não é o trabalho atrelado a dispositivos como emprego ou salário que deve ser priorizado, mas o trabalhar como oportunidade de experiência singular.

Mesmo com uma finalidade, o trabalho oportuniza desafios sobre como se colocar diante deste algo a ser feito, processo que é orientado por normas. As normas podem ser compreendidas como noção que abarca distinções permanentes entre polaridades, alimentando um sistema com pretensões de poder que exige obediência sob mecanismos de coerção que ganham vestes de verdade (Foucault, 1987; 2008). No contexto laborativo, as normas implicam o trabalhador em uma relação que não será de passividade, mas de apropriação. Ao mesmo tempo, as normas têm um caráter dinâmico que as colocam atentas às transformações, para que possam (re)adequar-se, em um jogo de apreensão e normalização das experiências em uma captura para sujeição de qualquer inventividade laboral. As normas que guiam o trabalhar, mesmo quando rasas em sustentações, são rígidas em suas exigências, causando confrontações entre o previamente definido e o posteriormente realizado. De conduta, posturas, resultados e competência, as normas são operadores circundantes construídos por instâncias reguladoras que travestem seus posicionamentos de verdades.

No contexto de vida capitalista, os processos de prescrição, inventividade e (r)estabelecimento da norma são a essência da articulação entre trabalho, trabalhar e sujeito que trabalha. Dessa forma, defendemos que o trabalho não é estático, tampouco o trabalhar. Mesmo com a mais rígida orientação para a realização de uma atividade, não há obediência fria às suas imposições. Pelo contrário, são os movimentos constantes e diversos que dão ao trabalhar o imperativo de engenhosidade inventiva, e ao sujeito que trabalha, o ensejo da experiência singular. A positividade do trabalho está nas criações diante das normas, inclusive de novas normas, que são espaços de experimentações subjetivas e de potencialidade para o questionamento das verdades. A possibilidade criadora que o trabalho oferece é de grande relevância para a manutenção da saúde do sujeito que trabalha, porém é fundamental o questionamento sobre "saúde através de qual trabalho?" (Dejours, 1993, p. 102).

A partir da constituição do Estado Moderno e da gênese e do desenvolvimento de novas formas de relação capitalista, notamos cada vez mais a demanda por um homem adaptado aos ideologismos do capital. Foucault $(1987 ; 2008)$ aponta como a lógica capitalista utiliza intensamente o dispositivo disciplinar como estratégia de organização da vida coletiva, ou seja, impõe normas aos indivíduos como forma de obter docilidade e obediência à ordenação social configurada a partir de formas regulamentadas de vida (Foucault, 1987; 2008). Dessa forma, qualquer processo de subjetivação construído nesse contexto se torna, paradoxalmente, um jogo diante das normas que sujeitam e, ao mesmo tempo, possibilitam uma existência. O capitalismo opera submetendo os indivíduos a formas de controle que não acontecem somente no corpo e pelo corpo biológico dos indivíduos, mas também no corpo social, político, subjetivo e utilitário do trabalhador, tornando-se este obediente, mas, contraditoriamente, ganhando visibilidade.

O trabalhar pronuncia diversos aspectos da vida psicológica, social e política dos indivíduos, sendo oportunidade para a invenção e reinvenção de si. Sua presença nos discursos da saúde não é recente, e sua função vinculante e constitutiva de componentes de práticas, teorias, aparelhos e sujeitos o coloca em posição de ser, potencialmente, uma estratégia de cuidado. No entanto é penoso vincular a possibilidade inventiva do trabalhar aos discursos utilitários do mercado de trabalho contemporâneo, que privilegia produtividade em 
detrimento da experiência singular e acaba por excluir os que não conseguem ou querem pactuar com isso, ou seja, "como incluir em um mercado de trabalho excludente?" (Santiago \& Yasui, 2011). Esse é o mais importante desafio a que o trabalho como estratégia de atenção em saúde mental precisa produzir enfrentamentos, diante de um cenário contemporâneo em que modelos de gestão valorizam posturas e relações em que constrangimentos e excessos de exigências dificultam a experiência singular do trabalho, assim como sua expressividade (Mendes \& Araújo, 2012; Gama, Mendes, Lazzarini, \& Vieira, 2019).

\section{Política Pública e Biopolítica}

As discussões sobre políticas públicas ganharam visibilidade nas últimas décadas. No Brasil, a partir das décadas de 1970/1980, vivemos processos de redemocratização da sociedade. O Estado, como importante ator social, foi convocado a criar novas formas de legitimidade para sua intervenção no social. Nesse ensejo, coloca-se a tarefa de conceituar política pública, não havendo consenso na literatura. As políticas públicas são definidas diversamente a partir da perspectiva que se assume. Como escolha de definição mais palpável, nós as compreendemos como ações planejadas do Poder Público com o objetivo de enfrentar situações consideradas problemas e que ganham relevância de alguma ordem em determinado momento histórico (Souza, 2007), ao tentar gerir os embates, imanados e virtualizados, da relação entre Estado, sujeitos de direitos e mercado econômico. Marcadas em um determinado momento histórico, as políticas, assim como as problemáticas das quais tentam dar conta, são evidências do que se julga importante e merecedor de ser foco de atenção e intervenção.

Na perspectiva foucaultiana (Foucault, 1986; 2008), o Estado não é o detentor ou propagador do poder, mas parte de um conjunto relacional em que o governo dos indivíduos é constituído, com suas fronteiras traçadas por sua razão governamental, ou governamentalidade: na soberania do poder em seu governo da morte, no Estado medieval e na sofisticada arte de condução de condutas, no Estado moderno. Com a modernidade, o Estado é solicitado a mediar interesses que evidenciam seus limites de governamentalidade quanto ao governo da vida, colocando o questionamento, para si e para a sociedade, do que é e do que não é da esfera do Estado. Somente na segunda metade do século XIX que a ação estatal, nas sociedades ocidentais, é definida e legitimada por uma racionalidade que promove um questionamento daquilo em que seria útil intervir e daquilo sobre o qual não se deveria agir de modo algum. Em uma emergência da biopolítica, enquanto ação política de legislar sobre o corpo biológico da população (Foucault, 2008), há a extensão desse espaço de exercício do poder para a vida dos indivíduos por meio das legislações e políticas públicas.

A forma de exercer o poder biopolítico é fundamental na emergência dos Estados modernos e do capitalismo, em que os corpos e as vidas, alvos de intervenções contínuas, são mergulhados em campos de visibilidade: natalidade, longevidade e mortalidade como intentos da higiene pública; velhice, acidentes e doenças, da assistência e seguridade social, entre outros. Foucault (2008) sinaliza como que, na biopolítica, as pessoas perdem "o direito sobre o seu próprio corpo, o direito de viver, de estar doente, de se curar e morrer como quiserem" (p. 96). Assim, a letra jurídica versará sobre um fazer viver, preferencialmente, normalizado: moralmente respeitado, medicamente saudável, socialmente seguro. "As políticas públicas 
se configurariam, em parte, na sociedade biopolítica, como as ações do Estado decorrentes da necessidade de intervir nos fenômenos da população para, ao promover autonomia, atuar conforme os interesses dos fisiocratas" (Guareschi, Lara, \& Adegas, 2010, p. 335).

Nos últimos séculos, as ações do Estado instauraram uma rede de tecnologias de poder normalizador e biopolítico, por meio de procedimentos de gestão, modelagem e captura dos indivíduos e da coletividade, em especial de grupos anormais e desajustados. As ações legais e políticas, assim como as instituições sociais e estatais, foram os operadores legitimados da intervenção deste Estado na sociedade por meio do estabelecimento de direitos civis, sociais e políticos, em um processo que é de instauração do Sujeito de Direitos, amparado pelo regulamento de políticas públicas. Temos, desta forma, "um processo que aproxima diretamente Estado moderno, Políticas Públicas e Sujeito de Direitos na construção do elemento subjetivo das políticas públicas" (Guareschi et al., 2010, p. 337). Recentemente, nas tramas neoliberais desse mesmo Estado, o mercado econômico se tornou incisivo no emprego de esforços para a produção de sujeitos ditos autônomos, ao mesmo tempo em que foi fonte de morbidades sociais, constituindo um embate: o sujeito de direitos vê-se, subjetivamente, fixado como um homo oeconomicus. Homo oeconomicus indica, em primeira colocação quase literal, o homem economicamente ativo. Foucault (2008) esclarece ser o homo oeconomicus o homem empreendedor de si no mercado econômico contemporâneo, um homem mercadorizado pela lógica do capital. Nesse arranjo, o homem adere de forma voluntariamente forjada ao mercado econômico (em seus imperativos e exigências) e precisa valorizar e amplificar suas habilidades e capacidades produtivas para se tornar valorizado pelo mercado de trabalho como contribuinte à lógica do capital. Foucault (2008) denuncia a inversão das relações sociais em econômicas para afirmar que a biopolítica, por meio de políticas estatais, agiria incentivando a vida e aniquilando os movimentos considerados arriscados e perigosos (Foucault, 1996; 2008). Seria a emersão do indivíduo governável por meio das leis econômicas associadas às legislações.

Em empréstimo dessas discussões para o contexto da saúde, como política pública, o SUS está em implantação cotidiana, em um processo social de permanente construção, visto que os desafios do viver coletivamente impõem constantemente desafios à gestão em saúde para constituir respostas às demandas, que vão se transformando. Quando resgatamos, nesta discussão, a importância objetiva e subjetiva do trabalho, pensá-lo como estratégia de atenção em saúde e saúde mental torna-se evidente.

\section{Sentidos de um Projeto Político que Articule Trabalho e Saúde Mental}

Uma reconstituição da história da loucura pelo recorte da relação entre atenção em saúde e trabalho traz a percepção de que a sociedade capitalista constantemente utilizou a aptidão ou inaptidão para o trabalho como importante elemento para a definição de normalidade (Santiago \& Yasui, 2011). No universo das instituições psiquiátricas, Saraceno (1999, p. 21) afirma que "o trabalho em manicômios é tão antigo como o próprio manicômio". Quando analisamos os sentidos da estratégia trabalho como terapêutica na assistência em saúde mental, percebemos que eles responderam a chamados vários. Inicialmente, com o intento de ocupação do tempo e das mentes livres dos asilados no manicômio; posteriormente, no intento de prática curativa, sustentada em experiências de laborterapia, praxiterapia e tera- 
pia ocupacional orientadas para o disciplinamento da capacidade produtiva como indicativo de condição para a reinserção social; e por fim, guiados por princípios reformadores da assistência psiquiátrica para a atenção psicossocial, como iniciativas de produção de subjetividade e contratualidade social, com as oficinas terapêuticas sendo a modalidade mais presente (Costa \& Figueiredo, 2004; Santiago \& Yasui, 2011).

Ao abarcarmos os documentos de projetos políticos que articularam trabalho e saúde mental, torna-se importante esclarecer que, neste texto, sustentamos o entendimento de que as legislações e políticas públicas são pautadas, atravessadas e constituídas pela história, não havendo composição discursiva política fora de uma conjuntura histórica e social. No que tange ao universo legal da atenção em saúde mental no Brasil, defendemos que os discursos históricos dirigidos à questão do trabalho como estratégia terapêutica podem ser organizados em duas frentes díspares: uma anterior à Reforma Psiquiátrica, outra posterior. Vejamos.

\section{Trabalho como Estratégia de Atenção antes da Reforma Psiquiátrica}

Por meio da aprovação do Decreto 1.132, em 1903, temos a instauração da primeira legislação psiquiátrica brasileira e, assim, de jurisprudência específica sobre a alienação. 0 documento propôs reorganizar a assistência aos loucos mesmo que, em termos concretos, tal assistência ainda não fosse exatamente constituída - era dispersa e variada, sendo permeada por conflitos entre figuras socialmente distintas e autoautorizadas a exercerem posições de avaliar e encaminhar para internação aqueles por elas consideradas mentalmente adoecidos. Com isso, os hospícios, ainda tomados pela lógica caritativa, apresentavam elevados números de internos, que continuavam crescendo vertiginosamente (Amarante, 1996; 2000). Foi nesse contexto que o decreto de 1903 foi elaborado e submetido para aprovação por João Carlos Teixeira Brandão, um psiquiatra eleito deputado federal.

Em análise, o Decreto de 1903 traz para a competência do Estado a alienação mental, ao mesmo tempo em que faz frágeis delineamentos de uma cidadania dos doentes mentais que se tornam, segundo a letra jurídica, tutelados pelo alienista, este positivado como elo entre os pacientes e a sociedade (artigo 1으) e protetor de ambos. Os loucos, negativados como conhecedores de si, são esvaziados quanto à capacidade de, além de gerir suas vidas, gerir seus bens (artigo 4으). Ações essas guiadas pelo discurso de proteção, desempenhada pelos alienistas e pela instituição asilar. O documento inaugura legalmente a psiquiatrização do louco, o que responde a chamados de um processo de normalização dos doentes mentais. Os processos de normalização são regimes de poder que se constituem por meio de sistemas de correção de indivíduos, objetivando homogeneizá-los a partir de um modelo normativo. Os dispositivos de normalização são instâncias produtoras do deve ser de indivíduos e grupos, que são essencializados e naturalizados, pleitos dos quais fazem parte instituições, como hospitais psiquiátricos, assim como disciplinas (que são conjuntos de saberes), como a psiquiatria e a medicina social (Foucault, 2008). Com a emergência do capitalismo, a gestão da vida e das populações demanda esforços. Táticas são criadas e operadas para colocar limites em uma sociedade em que os corpos ganham valor e visibilidade, sendo necessário controlá-los e administrá-los, para que a sociedade tenha sua existência assegurada. Essa tecnologia de poder foi denominada por Foucault (2008) de biopolítica. Tendo o corpo como objeto e a normalização como objetivo, os dispositivos biopolíticos operam por meio da 
interferência político-estatal no social e se constituem como táticas: "[A] teoria do governo não se trata de impor uma lei aos homens, mas de dispor as coisas, isto é, utilizar mais táticas do que leis, ou utilizar ao máximo as leis como táticas" (Foucault, 1986, p. 284).

Como potencializadores da vida e do viver, a saúde e a saúde mental ganham destaque - e o arcabouço jurídico alimentará essa posição -, além de se constituírem como respostas às demandas sociais, regulamentando os corpos e os fenômenos coletivos. A partir disso, a discussão que aqui promovemos assume o sentido crítico de que a ação estatal no social, por meio das legislações e políticas, cumpre um papel de patologizar e medicar esse social. Essa função de medicalização social da primeira legislação geral de jurisprudência específica sobre a assistência psiquiátrica pode ser identificada a partir de alguns elementos.

A direta preocupação com a manutenção do social é localizada logo no artigo 1ㅇ do Decreto de 1903, quando este sanciona que aquele que comprometer a ordem pública será recolhido aos asilos. Nota-se que o arranjo social é prioridade, justificando o ineditismo da deliberação do texto, que é reorganizar a assistência a alienados, exigindo o esforço de metrificar a questão, que se localiza nas repetitivas solicitações de quantificações sobre os enfermos, as descrições de suas características físicas e de seus indicativos de loucura (artigo 2ํ) e no detalhamento utilitário organizativo das instituições psiquiátricas que produzirão a assistência aos asilados (artigo 14) (Decreto 1.132/1903). A exigência do levantamento de informações sobre o interno, sua vida e sua doença alimenta o campo de visibilidade que o doente mental adentra legalmente. Sua vida, mas não sua existência, visto que, apesar de solicitar dados que poderiam denotar um interesse por sua particularidade, o documento em nenhum momento lança a iniciativa de dar voz ao alienado: o administrador do asilo assume funções, o juiz de direito, os peritos de polícia e, sobretudo, o alienista, não havendo discurso autorizado do sujeito adoecido que ganha visibilidade jurídica, mas a partir de uma vida tratada como indigna. Especificamente sobre a temática trabalho, esta, ao se restringir à solicitação de poucos dados laborativos quando da internação do indivíduo adoecido, rumina o discurso da valorização social a partir da profissão ou atividade profissional realizada. No entanto, por inaugurar o arcabouço jurídico sobre a loucura, torna-se importante trazer tal decreto para essa discussão, mesmo que ele abarque o trabalho de forma frágil.

Nas décadas seguintes, poucas alterações ocorreram na legislação federal direcionada à questão mental. Em julho de 1934, o Decreto de 1903 foi revogado pelo Decreto 24.559/1934, que dispõe sobre a profilaxia mental, a assistência e proteção aos mentalmente adoecidos. Nesse documento, quando comparado ao de 1903, o modelo assistencial psiquiátrico brasileiro é juridicamente mais bem estabelecido como hospitalocêntrico, com a internação sendo obrigatória aos alienados e, inclusive, aos considerados indivíduos suspeitos que perturbem a chamada ordem e moral pública (artigo 7ํ). Há, também, a reafirmação da incapacidade do louco, o que consolida o psiquiatra como perito da loucura. Nesse momento, a produção de tecnologias para que o Estado operasse seu projeto de promoção do bem-estar social necessitava da identificação de parcelas vulneráveis da população. Eram segmentos a serem guiados e estimulados para caminhos normalizados: mais saudáveis e moralmente desejáveis. Se a base da biopolítica está nas normas, são as anormalidades que devem ser gerenciadas em processos de recuperação, reabilitação e ressocialização (Foucault, 1987; 2008). 
A racionalidade política do Estado se faz presente no Decreto 24.559/1934, que, conforme nossas reflexões, é operado por três importantes aspectos. O primeiro é o contexto social, quando o país inicia um período histórico marcado pelo nacionalismo e por ações de nacionalização dos indivíduos, bem como de restrição às liberdades individuais. Como segundo contribuinte, a partir da década de 1930, a psiquiatria brasileira aproxima-se cada vez mais do alienismo alemão e seu eugenismo com argumentações pautadas por características étnicas e sociais que produziram no país uma releitura do fenômeno da loucura. Como terceiro componente, temos a Liga Brasileira de Higiene Mental (LBHM), que, nas décadas de 1920-1930, sustentou o ideário psiquiátrico preventivista no país, visando à prevenção, à eugenia e à educação moral e mental de indivíduos e grupos familiares (Amarante, 2000).

Em um contexto marcado pelo julgamento das questões individuais e grupais e pela forma como elas poderiam interferir no terreno social, a composição do Decreto de 1934 reflete uma lógica de prevenção em que a potencialidade do risco passa a ser uma preocupação eugenista. Os psiquiatras, em especial por meio da voz da LBHM, faziam apelos para intervenções políticas que pudessem solucionar as questões identificadas, a partir de então, como psiquiátricas. "A medicina mental ratificou em sua definição de doença mental a equação doente mental-perigo social. Sendo assim, a definição jurídica não poderia deixar de reafirmar a sua presença" (Amarante, 2000, p. 189). Se loucura e periculosidade se tornam relacionadas, o tratamento psiquiátrico assume posição de punição. Para Foucault (1996), a noção de periculosidade é evidência analisadora da emergência da norma, em que, mais do que o fato ou o ato, interessa as virtualidades do perigo (Foucault, 1996).

O Decreto 24.559 legalmente indica a estratégia terapêutica chamada assistência familiar, que contribuiu para o modelo institucional conhecido como Colônia de Alienados. Como microssociedades, as Colônias eram espaços de convívio e afetos controlados, livres dos excessos da vida urbana. No virtuosismo da vida rural, famílias substitutivas eram treinadas pelos psiquiatras para, com ensinamentos morais, contribuírem para o restabelecimento dos adoecidos. A dedicação ao trabalho (em especial o braçal) era vista como um empreendimento curativo fundamental nesse contexto. Com internação permanente, os loucos tinham a riqueza econômica de seus trabalhos garantindo seu sustento e sua bagagem moral modelada pelo círculo familiar artificial (Santiago \& Yasui, 2011).

As legislações psiquiátricas brasileiras de 1903 e 1934 são exemplos de exercícios de formas oficiais de governo de indivíduos e grupo, narrando o corpo biológico da loucura. Mais do que a assistência psiquiátrica, os textos proferem o bom controle e a modelagem da vida a um modelo cientificamente bem específico de sociedade, sendo documentos exemplos de discursos normalizadores. No âmbito do trabalho-tratamento em saúde mental, afirmamos que, no primeiro decreto, temos os alicerces que, no segundo, são erguidos enquanto operadores laborais com propósitos de ajustamento, com foco não na cura, mas na contenção dos desvios e dos desviantes com o empenho nas atividades de laborterapia, refletindo a adequação social do enfermo. Isso se evidencia quando notamos que as ações de trabalho eram com finalidade de manutenção do próprio manicômio ou, ainda, de internos realizando atividades agrícolas em propriedades rurais próximas ao manicômio, com remuneração para a instituição asilar, e não para o paciente (Amarante, 1996; Santiago \& Yasui, 2011). 


\section{Trabalho como Estratégia de Atenção a partir da Reforma Psiquiátrica}

As décadas posteriores aos anos de 1930 presenciaram, de forma cada vez mais intensa, iniciativas reformadoras da assistência psiquiátrica que apontavam o modelo asilar como violento e cronificante. Nos anos de 1950, ineficácia e centralização geográfica e assistencial caracterizavam as políticas de saúde mental no Brasil (Amarante, 2000), que ainda pouco se deixaram influenciar pelas discussões europeias de desinstitucionalização. No fluxo desenvolvimentista que percorria o país, intensificaram-se esforços para o resgate ou organização da capacidade laboral de internos asilados em um adestramento para o trabalho. Objetivos visualizados na organização arquitetônica dos hospícios e a crescente preocupação com a destinação de espaços físicos para a realização de atividades das mais diversas, como trabaIhos manuais, agrícolas e, sobretudo, de manutenção da instituição (Amarante, 2000).

Ainda nos anos de 1950, iniciou-se o direcionamento de esforços políticos para corrigir a realidade assistencial psiquiátrica brasileira. Como parte desse movimento, em 1963 aconteceu a III Conferência Nacional de Saúde (CNS), com tema sobre a situação sanitária da população brasileira. Na saúde mental, a III CNS apontou a necessidade de um sistema ambulatorial, além de serviços de praxiterapia extramanicomial (Amarante, 2000). Com a ditadura militar, a partir dos anos de 1960, a assistência em saúde mental foi ampliada em uma organização de psiquiatria de massa calcada em uma política que incluía poucos e excluía muitos. O modelo hospitalocêntrico foi fortalecido pela psiquiatria altamente rentável de uma indústria da loucura (Amarante, 1996; 2000), caracterizada por internações de longa permanência, cronificantes e de preponderância medicamentosa, aspectos que garantiram a retroalimentação do sistema, que somente vivenciou crises a partir dos anos de 1970. Em um contexto de efervescências políticas e sociais, o Brasil foi palco de mobilizações que produziram questionamentos quanto ao modo de vida. Em entrelaçamento, ações até ali preponderantes de assistência psiquiátrica foram descontruídas em suas possibilidades. Os próprios trabalhadores da área reunidos propuseram formas contra-hegemônicas de olhar e cuidar da loucura. Seus questionamentos foram acompanhados por denúncias das condições de tratamento nos manicômios. Da mobilização desses profissionais, foi constituído, em fins da década de 1970, o Movimento dos Trabalhadores da Saúde Mental (MTSM), considerado por Amarante (2000, p. 51) como "ator e sujeito político fundamental no projeto da Reforma Psiquiátrica brasileira". Também em 1970, o MTSM deu origem ao Movimento de Luta Antimanicomial, que nasceu marcado pelo resgate da cidadania daqueles em sofrimento. Entre os esforços para repensar a saúde no Brasil, outras quatro CNS aconteceram até 1980. Espaços de discussão e proposição de diretrizes, suas deliberações orientaram a elaboração de ações prioritárias nos âmbitos do governo, com destaque para a 8a Conferência, em 1986, e suas contribuições para a instituição do SUS, em 1990. Dessa forma, as CNS se tornaram espaço privilegiado que fomentou a emergência estrutural, teórica e legal de noções caras à atenção em saúde e saúde mental como hoje a conhecemos (Amarante, 1996; 2000).

O SUS foi estabelecido com princípios básicos de universalidade de acesso, integralidade e equidade do cuidado, descentralização dos serviços e participação social em uma nova concepção de saúde (Ministério da Saúde, 2004). Mais tarde, a Lei 10.216, de 2001, dispôs sobre os direitos das pessoas com sofrimento psíquicos intenso e redirecionou o modelo assistencial em saúde mental, ficando conhecida como Lei da Reforma Psiquiátrica. Em um 
contexto de emergências, Amarante e Torre (2001) afirmam que a configuração e articulação de várias situações compuseram novos caminhos para a saúde pública em um Brasil redemocratizado: duas CNS, em 1987 e 1992; a proposição do SUS, em 1988; e a movimentação de profissionais da saúde mental. A discussão sobre a cidadania dos sujeitos com sofrimento psíquico logo surgiu como uma temática necessária de ser aprofundada.

Com a aprovação da Lei 10.216/2001 e a revogação do Decreto de 1934, foi constituído, finalmente, um instrumento legal federal para a revisão da assistência em saúde mental. Tal lei, ao apresentar princípios fundamentais de direitos humanos para as pessoas em sofrimento psíquico, colocou à luz a preocupação com a vida e a subjetividade delas. A constituição e expressão de sua existência passaram a ser legisladas em discurso que colocou o cotidiano, os laços e as relações sociais em um lugar de reconhecimento legal, com o Estado sendo responsabilizado por tornar a intenção expressa na letra jurídica em gesto (artigo 3으). Com relação ao modelo assistencial proposto, a legislação transformou a anterior centralidade hospitalar em posição de coadjuvante, impondo mecanismos de controle aos hospitais e às internações, que não poderiam mais ocorrer em instituições asilares (artigo 6ㅇ). Essa estratégia se baseou na orientação para a integralidade do tratamento, que deveria ocorrer preferencialmente em dispositivos diversificados, comunitários e multidisciplinares, visando permanentemente à reinserção social a partir de um processo de reabilitação psicossocial (artigo 50). Além disso, com a reconstrução de práticas e saberes com o objetivo da reinserção social, o documento apresentou a alta planejada e reabilitação psicossocial assistida. Os laços familiares e comunitários são citados como dimensões importantes nos processos e, nesse aspecto, a dimensão trabalho é colocada com destaque. Quando o trabalho é nominalmente citado (artigo 2 o), ele está atrelado às ideias de positividade por sua importância na vivência pessoal e social com dignidade e cidadania daqueles em sofrimento.

A legislação federal de 2001, como operador biopolítico qualificado de tecnologia de inclusão (Foucault, 2008), tem potencialidade para produzir reinserção social ao apontar estratégias diferenciadas de atenção em saúde mental, mas, enquanto discurso concreto, ela fez orientações e criou princípios de regulação, o que não é pouco, mas sim insuficiente por si só, já que não há transformação social unicamente por meio do discurso ou de um ato formal. Mesmo com a nomeação do Estado e com as expectativas na confecção de políticas específicas, estas podem não se mostrar suficientes, como de fato muitas vezes não o são quando encontram os desafios do cuidado cotidiano, como a literatura evidencia (Saraceno, 1999). Inclusive, um dos pontos de fragilidade da Lei 10.216 pode ser justamente a questão do trabalho em seu papel balizador de reinserção social. O desafio de incluir o sujeito em sofrimento em um mercado de trabalho excludente por excelência é exemplo do embate de forças no âmbito dos discursos e das práticas de se pensar o trabalhar como estratégia de atenção (Santiago \& Yasui, 2011), e sobre isso a Lei não chega a versar.

A partir do SUS e da Lei 10.216/2001, uma Política Nacional de Saúde Mental foi constituída. Esta preconizou uma rede de atenção ampliada de base comunitária e territorial em cuidados desinstitucionalizados, auxiliando na construção de um outro lugar social para a loucura, em que as relações de produção e reprodução da vida foram reconfiguradas. A invenção desse outro lugar, que é também o de reinserção social, precisará de estratégias e programas que, no âmbito do trabalho, serão as de cooperativas de trabalho, inclusão social a partir do trabalho e centros de convivências, além de outros. Com isso, a questão do 
trabalho concretamente ganha espaços para se articular como exercício da cidadania, dos direitos humanos e da produção de subjetividade e contratualidade social.

Pouco após da Lei de 2001, foi realizada a 3ạ Conferência Nacional de Saúde Mental (CNSM), com discussões específicas sobre o trabalho na saúde mental não manicomial. Nessa Conferência, tendo por base seu relatório final (Ministério da Saúde, 2001), a expressão reabilitação psicossocial entrelaça os esforços para valorizar a complexidade da existência humana, dos quais o trabalhar é considerado por se inscrever no cotidiano das relações sociais e da manutenção de autonomia. No entanto há pouco aprofundamento de que trabalho e de que condições concretas se fala, em um jogo de ele estar presente (nominalmente) e estar frágil (conceitualmente). Nas discussões específicas sobre trabalho, as palavras "reabilitação psicossocial" não são colocadas, mas sua potência para a (re)construção de laços sociais é objetivada, ao afirmar que o "processo de Reforma Psiquiátrica requer a implementação de políticas públicas que garantam e consolidem a criação de Programas de Geração de Renda e Trabalho [...], visando os processos de produção de autonomia e de direitos de cidadania" (Ministério da Saúde, 2001, p. 45). Em suas especificidades, as proposições envolvendo trabalho apresentam como finalidade o mercado formal, em que são sugeridos caminhos, tais como a constituição de leis que incentivem formação e capacitação profissional aos usuários da saúde mental. A presença e os sentidos das atividades de trabalho no contexto da atenção, a partir da Conferência, conduzem-nos para a percepção de um processo de normalização via capacidade laboral, pela transferência do indivíduo da segregação do manicômio para a alienação do mercado de trabalho. Além disso, pelo discurso, o trabalho na saúde mental seria paliativo até o alcance do vínculo formal, no formato de emprego. Outro ponto envolve a variação dos termos no documento. Ora se coloca geração de renda e trabalho, ora geração de trabalho e renda, alimentando o questionamento aqui sobre o que se está priorizando, trabalho ou renda? A ordenação propaga um discurso implícito. Geração de renda e trabalho suscita que o trabalho seja efeito da renda, ou seja, busco ou necessito da renda, por isso, realizo um trabalho. Enquanto geração de trabalho e renda inverta a proposição, com a renda tornando-se efeito de um trabalho, consequência de uma relação entre sujeito e uma atividade que potencialmente pronuncia variados aspectos da vida psicológica, social e política dos indivíduos, oportunizando o que se almeja com o trabalho enquanto estratégia de atenção em saúde: aquele que propicia a invenção e reinvenção de si.

Dos atos legais federais que norteiam a atenção em saúde mental indicando nominalmente a estratégia trabalho, a Lei n. 9.867/1999 é o primeiro. Tal documento dispôs sobre a criação e o funcionamento das cooperativas sociais. Originalmente, o projeto foi de iniciativa do deputado Paulo Delgado e apresentou uma analogia com as experiências da reforma psiquiátrica italiana de empresas sociais. Mesmo com a direta disponibilidade em discorrer sobre as cooperativas sociais, a lei em questão não apresenta uma conceituação, indicando apenas sua finalidade (artigo 1ㅇ) , a de "inserir as pessoas em desvantagens no mercado econômico, por meio do trabalho, fundamenta[ndo]-se no interesse geral da comunidade em promover a pessoa humana e a integração social dos cidadãos" (Ministério da Saúde, 2004, p. 15). Quanto a quem seriam as pessoas em desvantagens, o documento lista perfis variados (deficientes de distintas condições, pacientes psiquiátricos crônicos e de longa permanência, egressos do sistema prisional, adolescentes em idade adequada ao trabalho e situação familiar difícil do ponto de vista econômico, social ou afetivo). A expressão 
"pessoas em desvantagem" indica uma condição existencial fixa, constituída como uma rotulagem identitária (Ministério da Saúde, 2004). Anos depois, na I Conferência Temática de Cooperativismo Social, realizada em 2010, saiu a proposta, nunca acatada, de substituição do termo para pessoas em situação de desvantagem, como tentativa de privilegiar o dinamismo da existência humana. Em análise, afirmamos que o documento opera com enunciados que agenciam sentidos de um processo de adaptabilidade ao trabalho, como evidenciado no artigo 3ำ, quando se afirma que as cooperativas sociais organizarão suas atividades quanto aos "horários e jornadas, de maneira a levar em conta e minimizar as dificuldades gerais e individuais das pessoas em desvantagem que nelas trabalharem, e desenvolverão e executarão programas especiais de treinamento com o objetivo de aumentar-lhes a produtividade" (Ministério da Saúde, 2004, p. 16). Nota-se como é protagonista a realização da atividade de trabalho a partir de parâmetros de prescrição produtivista, e não, mais uma vez, o processo de trabalhar em sua potencialidade. Defendemos que não se desconsidere o viés de quais são os resultados materiais do trabalho realizado?, mas esses não podem ser priorizados como única ou primeira medida da experiência trabalho na saúde mental.

No ano de 2000, a Portaria Ministerial n. 106 criou Serviços Residenciais Terapêuticos em Saúde Mental, que, em suas diretrizes, apresentaram a reinserção no trabalho como um dos pontos da reabilitação psicossocial a ser contemplado, em que a experiência trabalho, junto a outras, é reconhecida como auxiliadora na consolidação do abandono do modelo asilar. Para isso, orientam-se três frentes de ações relacionadas ao trabalho: que projetos de reinserção no trabalho sejam constituídos; que parcerias com outros dispositivos institucionais e sociais sejam estabelecidos; e que sejam estimuladas políticas de intercâmbio e cooperação entre Estado e sociedade. Apesar de aparentemente mais ampliado que os documentos anteriores quanto às intersetorialidades que envolvem o trabalho, uma ausência se repete: não há conceituações de trabalho. Inclusive, aqui, também, noções distintas em suas lógicas são utilizadas como sinônimos, por exemplo, a citação de reinserção no trabalho (artigo 4으) e inserção no mercado de trabalho (artigo 14ㅇ) (Ministério da Saúde, 2004).

Entre os anos de 2003 e 2005, o suporte financeiro para as ações de reabilitação e inserção social pelo trabalho será tema de textos legais da saúde. A Lei 10.708/2003 tratou das condições de envolvimento dos sujeitos com projetos de trabalho e renda (por meio da instituição do auxílio-reabilitação psicossocial). Já a Portaria Ministerial 1.169/2005 tratou do incentivo financeiro aos municípios que desenvolvessem projetos de inclusão social pelo trabalho. Ambos os documentos, em suas intenções, trazem alguns destaques. Tentam dar materialidade para a manutenção dos projetos e da participação dos usuários neles. Para os municípios e estados brasileiros que colocam tais políticas em ação, a destinação de incentivo financeiro impulsiona o olhar público para a questão. Consideram possibilidades coletivas não capitalistas, como empreendimentos solidários e autogestionários. Propõem diálogos em uma rede intersetorial de serviços e políticas públicas (Ministério da Saúde, 2004).

Uma colocação recorrente nas publicações oficiais nos últimos anos foi a prerrogativa de desenvolver ou apoiar iniciativas intersetoriais que contemplassem o trabalho. Em alguns documentos, inclusive, é citada a prerrogativa de integração da política de saúde com outras. São exemplos de publicações que colocam tal orientação, entre vários possíveis, a Lei Federal 11.343/2006 (que institui o Sistema Nacional de Políticas Públicas sobre Drogas) e publicações (Portarias Ministeriais 154/2008 e 2.843/2010) que tratam dos Núcleos de 
Apoio à Saúde da Família (Nasf). Como destacada iniciativa intersetorial, em 2005, a Portaria Interministerial n. 353/2005 (assinada pelo Ministério da Saúde e Ministério do Trabalho e Emprego) instituiu o grupo de trabalho de saúde mental e economia solidária e estabeleceu atribuições articuladoras entre as áreas. Instaurado com a argumentação de que ambas as políticas, economia solidária e reforma psiquiátrica, possuem eixos similares e potentes para alterar e ampliar as condições concretas de vida de segmentos menos favorecidos, esse grupo de trabalho criou a Rede Brasileira de Saúde Mental e Economia Solidária (artigo 2ำ), que atuaria com alguns propósitos, como o de constituir canais e redes de consumo de produtos e serviços, fruto das iniciativas e dos projetos de trabalho na saúde mental (Ministério da Saúde, 2010), com condições orientadas e apoiadas pela Secretaria Nacional de Economia Solidária (Senaes), criada em 2003 e vinculada ao Ministério do Trabalho e Emprego.

Após cerca de 30 anos de Reforma Psiquiátrica, essa é compreendida como consolidada (Onocko-Campos, 2019). Desde 2006, os recursos com os serviços comunitários se tornaram maiores do que com as instituições psiquiátricas. Muitos hospitais psiquiátricos, compreendidos como ineficientes, foram fechados. Houve a ampliação dos serviços de atenção nos territórios, fortalecidos pela instauração da Rede de Atenção Psicossocial (Raps) a partir de 2011, contando com a retaguarda do Apoio Matricial. Ocorreu a construção de políticas e serviços voltados para a população com problemas relacionados ao álcool e outras drogas, o que significou a criação de muitos Centros de Atenção Psicossocial Álcool e outras Drogas (CAPS ad), também a partir de 2011. Todos exemplos de políticas e dispositivos que direta ou indiretamente contemplam o trabalho como estratégia de atenção em saúde mental. No entanto, nesses anos, também houve uma expansão desigual dos serviços e a insuficiente construção e implementação de estratégias efetivas de participação de usuários e familiares no processo de atenção em saúde mental, além do constante subfinanciamento estatal na saúde mental (Onocko-Campos, 2019). Todavia, em meio aos processos, o trabalho como estratégia de atenção em saúde mental se constituiu potente por meio de experiências práticas inovadoras e bem-sucedidas na promoção do protagonismo e da autonomia dos sujeitos em sofrimento psíquico pela via do trabalho. São exemplos: o Projeto Trabalho, criado em 1989 e existente até os dias de hoje, ligado ao Núcleo de Projetos Especiais do Caps "Prof. Luís da Rocha Cerqueira" (Caps Itapeva), na cidade de São Paulo; e, ainda, o Núcleo de Oficinas e Trabalho (NOT), constituído em 1993 como braço do Serviço de Saúde "Dr. Cândido Ferreira" (Campinas, SP).

\section{Algumas Considerações}

Não há discurso jurídico ou concretude de uma lei ou política que exista sem a aceitação da sociedade que a reconheça e lhe dê existência na esfera das relações cotidianas. Por isso, Foucault (1986) afirma que a letra jurídica e política é, essencialmente, abstração.

À guisa de nossas considerações, apontamos que a gestão em saúde, a partir de seus ditames constitucionais e de política pública das últimas décadas, tem enfrentado o desafio de legislar no social, sem legislar o social. Legislar no social é reconhecer e respeitar (e não normalizar) formas singulares de vivenciar a saúde e a doença. Para isso, o desafio das políticas públicas é orientar a atenção em saúde a partir de nuances não mercantilizadas de saúde. Em um diagnóstico biopolítico do presente, as políticas públicas como ação estatal têm dificuldade em se desvencilhar das interferências do mercado econômico de racionalidade 
neoliberal. Dessa forma, o sujeito de direito reformulado como homo oeconomicus torna-se ilusório e normalizadamente autônomo em sua submissão, ao satisfazer as necessidades do mercado, conquistando seu lugar no arranjo econômico, sendo, nessa medida, um indivíduo modulado e ajustado em seu modo de pensar e viver.

No que tange ao discurso jurídico, antes do movimento da Reforma Psiquiátrica brasileira, a legislação de assistência psiquiátrica estava a serviço do objetivo de medicalizar a loucura e o louco, inclusive em suas inserções no social, com o trabalho sendo parte fundamental deste. Nos escritos legais, o foco não era a cura, mas a moralização, com dedicado esforço para a contenção dos desvios e dos desviantes. Quanto às atividades de trabalho no contexto da saúde mental, elas eram um importante instrumento tanto de medida de adequação existencial e social quanto de avaliação de eficácia dos tratamentos aplicados no espaço asilar e manicomial, sendo demarcadas em fenômenos de visibilidade das vidas degeneradas e como medida de adequação social.

A partir do final da década de 1980, com o SUS e a Lei 10.216/2001, o olhar e o entendimento sobre o sofrimento psíquico se ampliaram, incentivando tanto reflexões como experiências práticas diferenciadas quanto ao cuidado produzido na área de saúde mental, contribuindo e exigindo a elaboração, implantação e acompanhamento de políticas públicas. Desses momentos em diante, o doente mental, subjugado a saberes legalmente amparados e institucionalmente estabelecidos, foi reposicionado. No âmbito da dimensão trabalho, a produção discursiva legal e política da saúde mental assumiu diretrizes como a reabilitação psicossocial, utilizando neste processo, como um de seus principais instrumentos, a (re)inclusão social pelo trabalho. Todavia, a partir de então, o desafio é o de como contribuir para a inclusão social a partir do trabalho quando outros grupos, desempregados e subempregados, não a conseguem.

Cartografias das políticas públicas que contemplem o trabalho como estratégia de atenção em saúde mental evidenciaram a falta de uma homogeneidade conceitual de trabalho, das perspectivas do trabalhar, inclusive com um mosaico semântico de termos e expressões por vezes contraditórios, indicando a necessidade de discussões mais detidas dos conceitos e dos contornos teóricos a partir dos quais os discursos serão proferidos. Também estão presentes, nos documentos, referências ao acesso, à competência e à vivência do trabalho como uma jornada de linearidade adaptativa, desconsiderando a dinâmica da produção de si que o trabalhar oportuniza. Há demasiada valorização do mercado formal de trabalho, bem como uma discursividade que conceitualmente aproxima e, por vezes, textualmente identifica trabalho com emprego formal, em uma valorização do trabalho prescrito e atestado que a formalidade do mercado de trabalho tanto valoriza. Mesmo com reconhecido esforço político, infelizmente, a estratégia trabalho no contexto da saúde mental é discursivamente cercada de ambiguidades que não podem ser ignoradas. As políticas públicas certificam direitos, tentam assegurar articulações, porém não se opera uma transformação social unicamente a partir de atos legais. Mas, ao constituírem diretrizes de atuação, tais documentos norteiam, sim, as estratégias construídas no cotidiano dos serviços, como um breve levantamento da literatura sobre experiências exitosas de geração de trabalho e renda no contexto da saúde mental evidenciária.

Um outro pacto social da relação entre sofrimento psíquico e trabalho precisa ser estabelecido. Esse caminho já começou a ser percorrido, mas ainda há uma considerável jornada para que a política pública aprenda a falar sobre os sujeitos sem fazê-los refém: precisa 
substancializar os indivíduos sem sujeitar sua potência criativa e criadora, precisa apreciar a realidade social sem recriá-la higienicamente, precisa construir formas de tratar os desiguais desigualmente, pois, ao igualizar a diferença, apagam-se as particularidades.

Embora este texto tenha atingido os objetivos propostos, vale ressaltar que sua principal limitação foi a de não conseguir abarcar como o discurso político aqui destacado desdobrase no cotidiano dos serviços e das práticas de saúde mental, questão que necessita de ampliação de pesquisas e construções teóricas, as quais não foram contempladas aqui, devido aos limites deste texto. Outro ponto ainda se refere ao cenário da vida e do trabalho contemporâneo e como ele tem se mostrado especialmente difícil, com notícias de desmonte dos direitos trabalhistas, esvaziamento das ações coletivas e formalização de relações precarizadas de trabalho, como a jornada intermitente (Krein, 2018) e outras formas laborais, empurrando todos os trabalhadores para relações nocivas e potencialmente adoecedoras (Mendes, 2007). Pensar sobre como essas novas configurações do mundo do trabalho podem reverberar nas experiências de geração de trabalho e renda na saúde mental torna-se uma questão ainda a ser abarcada em um futuro próximo.

No âmbito das políticas e práticas de trabalho e saúde mental, o fim do Ministério do Trabalho e a transformação da Senaes em departamento do Ministério da Cultura, em 2019, fragmentaram as políticas de geração de trabalho e renda - contexto que se torna pior com as modificações nos últimos anos nas políticas de saúde mental, que já são lidas, como afirmado por Onocko-Campos (2019) e com o qual esses autores concordam, como colocando em risco não só a Reforma Psiquiátrica, mas a democracia.

\section{Referências}

Amarante, P. (1996). O homem e a serpente: Outras histórias para a loucura e a psiquiatria. Rio de Janeiro: Ed. Fiocruz.

Amarante, P. (2000). Loucos pela vida: A trajetória da reforma psiquiátrica no Brasil. Rio de Janeiro: Panorama/Ensp.

Amarante, P., \& Torre, E. H. G. (2001). A Constituição de novas práticas no campo da atenção psicossocial: análise de dois projetos pioneiros na Reforma Psiquiátrica no Brasil. Saúde em Debate, 25(58), 26-34. Disponível em https://rl.art.br/arquivos/542863.pdf

Costa, C. M., \& Figueiredo, A. C. (2004) (Org.). Oficinas terapêuticas em saúde mental: Sujeito, produção e cidadania. Rio de Janeiro: Contra Capa.

Decreto n. 1.132, de 22 de dezembro de 1903. (1903). Reorganiza a assistencia a alienados. Diário Oficial da União.

Decreto n. 24.559, de 3 de julho de 1934. (1934). Dispõe sôbre a profilaxia mental, a assistência e proteção á pessôa e aos bens dos psicopatas, a fiscalização dos serviços psiquiátricos. Diário Oficial da União.

Dejours, C. (1993). Por um trabalho, fator de equilíbrio. RAE: Revista de Administração de Empresas, 33(3), 98-104. Disponível em http://www.scielo.br/pdf/rae/v33n3/a09v33n3. pdf

Dejours, C. (2004). Subjetividade, trabalho e ação. Revista Produção, 14(3), 27-34.

Foucault, M. (1986). Microfísica do poder, 6a ed. Rio de Janeiro: Graal.

Foucault, M. (1987). História da loucura. São Paulo: Perspectiva. 
Foucault, M. (1996). A verdade e as formas jurídicas. Rio de Janeiro: Nau.

Foucault, M. (2008). Nascimento da biopolítica. São Paulo: Martins Fontes.

Gama, L. P., Mendes, A. M. B., Lazzarini, E. R., Vieira, F. O. (2019). (Im)possibilidade de investimento pulsional no trabalho: análise de um caso em clínica do trabalho. Trivium - Estudos Interdisciplinares, 11(1), 113-122. Disponível em https://dx.doi. org/10.18379/2176-4891.2019v1p.113

Guareschi, N. M. F.; Lara, L.; Adegas, M. A. (2010). Políticas públicas entre o sujeito de direitos e o homo œconomicus. Psico, 41(3), 332-339. Disponível em http://www.oalib. com/paper/2410430

Krein, J. D. (2018). O desmonte dos direitos, as novas configurações do trabalho e o esvaziamento da ação coletiva: consequências da reforma trabalhista. Tempo Social, 30(1), 77-104. Disponível em http://dx.doi.org/10.11606/0103-2070.ts.2018.138082

Mendes, A. M. B. (Org). (2007). Psicodinâmica do trabalho: Teoria, método e pesquisas. São Paulo: Casa do Psicólogo.

Mendes, A. M., \& Araújo, L. K. R. (2012). Clínica psicodinâmica do trabalho: O sujeito em ação. Curitiba: Juruá.

Ministério da Saúde (2001). III Conferência Nacional de Saúde Mental: Caderno Informativo. Brasília: Ministério da Saúde.

Ministério da Saúde (2004). Legislação em saúde mental: 1990-2004. Brasília: Ministério da Saúde. Disponível em http://bvsms.saude.gov.br/bvs/publicacoes/legislacao_mental.pdf Ministério da Saúde (2010). Legislação em saúde mental: 2004-2010. Brasília: Ministério da Saúde. Disponível em http://www.sesa.pr.gov.br/arquivos/File/20042010.pdf

Onocko-Campos, R. T. (2019). Saúde mental no Brasil: avanços, retrocessos e desafios. Cadernos de Saúde Pública, 35(11), 01-05. Disponível em https://doi. org/10.1590/0102-311X00156119

Santiago, E., \& Yasui, S. (2011). O trabalho como dispositivo de atenção em saúde mental. Revista de Psicologia da Unesp, 10(1), 195-210. Disponível em https://repositorio. unesp.br/handle/11449/126970

Saraceno, B. (1999). Libertando identidades: Da reabilitação psicossocial à cidadania possível. Belo Horizonte: Instituto Franco Basaglia/Te Corá.

Souza, C. (2007). Estado da arte da pesquisa em políticas públicas. In Hochman, G., Arretche, M., \& Marques, E. (Org.). Políticas públicas no Brasil. Rio de Janeiro: Ed. Fiocruz.

Recebido em: 24/07/2019

Última revisão: 17/12/2019

Aceite final: 21/01/2020

\section{Sobre os autores:}

Eneida Santiago: Doutorado em Saúde Coletiva pela Universidade Estadual Paulista Júlio de Mesquita Filho (Unesp-Assis). Mestrado em Psicologia e Sociedade e graduação em Psicologia, também pela Unesp-Assis. Professora adjunta da Universidade Estadual de Londrina (UEL), no Departamento de Psicologia Social e Institucional, e docente no Programa de Pós-Graduação Stricto Sensu em Psicologia (PPGPSI-UEL). Tem desenvolvido pesquisas na área de Psicologia, Trabalho e Saúde, com ênfase em Saúde Coletiva, Psicologia e Políticas Públicas, Saúde e Processos de Subjetivação e 
Intersetorialidade, atuando principalmente nos seguintes temas: Políticas Públicas e Gestão da Vida, Processos de Subjetivação e Trabalho, Saúde Mental e Saúde Coletiva, Intersetorialidade e Atenção em Saúde. E-mail: eneidasantiago2@gmail.com, Orcid: http://orcid.org/0000-0002-5296-4341

Silvio Yasui: Doutorado em Saúde Pública pela Fundação Oswaldo Cruz. Mestrado em Psicologia pela Universidade Estadual Paulista Júlio de Mesquita Filho (Unesp). Graduação em Psicologia pela Universidade de Mogi das Cruzes. Livre-docente em Psicologia e Atenção Psicossocial pela Unesp. Professor associado da Unesp-Assis. Tem experiência na área de Saúde Coletiva, com ênfase em Saúde Mental, atuando principalmente nos seguintes temas: Atenção Psicossocial, Reforma Psiquiátrica e Saúde Mental. E-mail: silvioyasui@gmail.com, Orcid: http://orcid.org/0000-0001-5015-6634 
